\title{
Smart Use and Sustainable Architecture of Wi-Fi in a Metropolitan City: Dhaka
}

\author{
Nazmus Sakib \\ Department of Computer \\ Science \& Engineering \\ Ahsanullah University of \\ Science and Technology \\ Dhaka, Bangladesh.
}

\author{
Jarin Tasnim Khan \\ Department of Computer \\ Science \& Engineering \\ Ahsanullah University of \\ Science and Technology \\ Dhaka, Bangladesh.
}

\author{
Paramita Basak Upama \\ Department of Computer \\ Science \& Engineering \\ Ahsanullah University of \\ Science and Technology \\ Dhaka, Bangladesh.
}

\begin{abstract}
Internet has become one of the basic needs of people in this modern world. They need internet to know about any unknown topic, place and person, get online study materials, and stay connected with their near and dear ones via social networking sites and IP calling services. Due to the availability of internet in every handheld electronic devices, number of internet users are increasing day by day. Dhaka, being the capital and a major metropolitan city of Bangladesh, has most population density as well as most internet users. There are 4-5 major mobile telephone service providers in this city who also offer internet services. People choose different service providers considering different reasons, such as: area coverage, call rates, internet packages and their prices etc. Sometimes people are leaving their usual area and entering such an area where their mobile telephone service provider will not be able to provide services. Then they need to stop using the SIM card of that service provider and take a new one from others. This is not convenient for any customer of any mobile phone company. This situation can be avoided if all such service providers are agreed to share their networks with each other throughout the city. This will provide service to any customer of any service provider even when it do not have network in some areas. This sharing does not require much financial support as it will be using the existing networks and some new Wi-Fi devices to support growing number of users.
\end{abstract}

\section{Keywords}

Internet, Mobile phone network, Mobile phone service provider, SIM Card, Wi-Fi, Routers, 3G and 4G network, Gateways, Handover, Data Service.

\section{INTRODUCTION}

\subsection{Telecom Industry of Bangladesh}

\subsubsection{Emergence of Internet Technologies in} Bangladesh

Mobile phone was first introduced in Bangladesh in the middle of 1990s. At that time only the rich people were blessed with the opportunity of using it. Today the cost of devices and call rates have been reduced to a large extent. Technology behind mobile phone has been changed several times, and Bangladesh has experienced the early ones named $1 \mathrm{G}$ and $2 \mathrm{G}$. Although most of the developed and some of our neighboring countries have been experiencing $3 \mathrm{G}$ for a handsome number of years, Bangladesh was not fortunate enough to have this technology so far. After a long cherished waiting, things have been changed as Bangladeshi telecom operator Teletalk launched 3G by 2012 [1]. Now-a-days some mobile phone companies as well as some Internet providers are providing $3 \mathrm{G}$ service to the people of Bangladesh. Still the percentage of area covering $3 \mathrm{G}$ network is too small.

\subsubsection{Frequency}

In 2009 there were only 50,000 fixed broadband Internet subscribers in Bangladesh [2].Those were the days when broadband Internet access was available, but the charges for high speed connections were higher than that of other south Asian countries. The situation is changing, though the cost is still too high to satisfy every type of user. In Bangladesh, broadband is legally defined as $128 / 128 \mathrm{kbps}$, which is not in line with the ITU's definition. Again, many broadband Internet services of Bangladesh may not be considered true broadband internationally [3].

\subsubsection{Network Use}

The current scenario of telecommunication transmission network (or data transmission system through mobile network) of Bangladesh is shown in the following table:

Table 1. Current Scenario of mobile network in Bangladesh

\begin{tabular}{|c|c|c|c|c|}
\hline Company & $\begin{array}{l}\text { Length of } \\
\text { Cables } \\
\text { (KM) }\end{array}$ & $\begin{array}{l}\text { District } \\
\text { Covered }\end{array}$ & $\begin{array}{l}\text { No. of } \\
\text { Drop- } \\
\text { off } \\
\text { Points }\end{array}$ & $\begin{array}{c}\text { Average } \\
\text { Utilizatio } \\
\text { n }(\%)\end{array}$ \\
\hline$\overline{\text { BTCL }}$ & $\begin{array}{c}1806(+65 \\
0)\end{array}$ & $\begin{array}{l}\text { 36(STM- } \\
\text { 4,STM-64 } \\
\text { Capacity) }\end{array}$ & 44 & \\
\hline $\begin{array}{c}\text { Grameenpho } \\
\text { ne } \\
\end{array}$ & 2251 & $\begin{array}{l}\text { 36(All divisions } \\
\text { covered) }\end{array}$ & 49 & 51 \\
\hline Banglalink & 1802 & $\begin{array}{c}\text { 23(Strong in } \\
\text { Khulna and } \\
\text { Barisal) }\end{array}$ & 43 & 39 \\
\hline Citycell & 1134 & $\begin{array}{c}\text { 17(Except } \\
\text { Barisal } \\
\text { Division) }\end{array}$ & 33 & 32.24 \\
\hline $\begin{array}{c}\text { Robi Axiata } \\
\text { Limited }\end{array}$ & 682 & $\begin{array}{c}\text { Robi Axiata } \\
\text { Limited,53 } \\
\text { Gulshan South } \\
\text { Avenue,Gulshan } \\
\text {-1,Dhaka-1212 }\end{array}$ & 21 & 44 \\
\hline $\begin{array}{c}\text { Railway } \\
\text { (leased by } \\
\text { GP) }\end{array}$ & 2014 & $\begin{array}{c}\text { 34(Except } \\
\text { Barisal } \\
\text { Division) }\end{array}$ & 66 & 52 \\
\hline $\begin{array}{c}\text { PGCB (Used } \\
\text { by GP) }\end{array}$ & 413 & $\begin{array}{l}\text { 5(Dhk- } \\
\text { Ctg,Cox's Bazar } \\
\text { Route) }\end{array}$ & 19 & 42 \\
\hline$\overline{\text { PGCB }}$ & 3314 & $\begin{array}{c}\text { Countryside(ST } \\
\text { M-1,STM-4 } \\
\text { Capacity) }\end{array}$ & 115 & - \\
\hline Teletalk & 160 & 9 & 8 & - \\
\hline Fiber@Home & 1200 & 23 & $\begin{array}{l}90(\text { in } \\
\text { progres } \\
\text { s) }\end{array}$ & - \\
\hline Total & 14776 & 59 & 490 & - \\
\hline
\end{tabular}




\subsubsection{Customer Requirements}

The percentage of Internet subscribers in Bangladesh from 2000 to 2013 are shown in the following graph [4]:

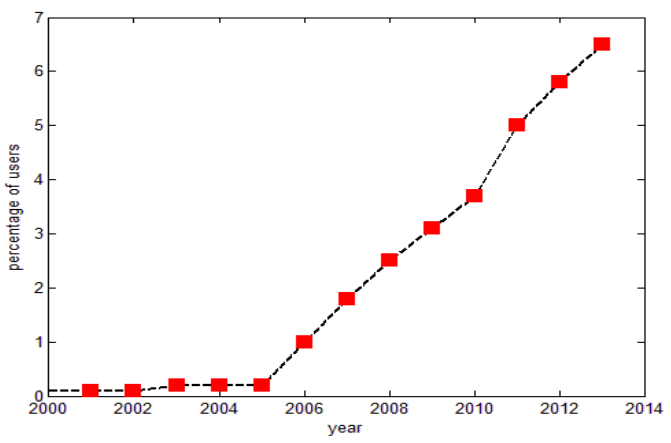

Fig. 1: Percentage of Internet users in Bangladesh

According to the above graph, only $0.1 \%$ of the population used the Internet in 2000s giving Bangladesh one of the lowest usage percentages in the world. This limited Internet usage is due to many factors including high costs, little local content, limited or poor service quality, lack of proper infrastructure and low literacy rates [5].

By 2011 however, the number of Internet users in Bangladesh had seen phenomenal growth and 5\% of total population started using Internet. It became possible mainly due to wide availability of mobile Internet access. Because fixed line penetration rates are very high, most Bangladeshi first experience the Internet via mobile services which cost relatively low. In 2010, about $90 \%$ Internet users of Bangladesh got their access using mobile phones [5].

\subsubsection{Current costs of Internet service}

In initial years, every ISP took US $\$ 250$ for registering an earning subscriber and US \$ 125 from a student subscriber. Some years later the rate dropped to US \$ 125 and US \$ 75, respectively. According to this data, the Internet charge became 7.5 cents per minute. Since December 1996 the government has imposed a $15 \%$ VAT on the online charge So including VAT the users need to pay 8.6 cents per minute for Internet access. Therefore, if a subscriber on average uses the Internet for one hour a day and 30 hours a month, his online bill per month will be US \$ 155 . This bill is still too much for a developing country with per capita annual income of US \$ 957.8 [6]. Moreover, because of low-speed telephone cables and around 40 phone lines connected with the $64 \mathrm{kbps}$ VSAT-based server, Internet speed becomes too slow and so, web browsing becomes very expensive [7].

\section{WI-FI BASED NETWORK OVER OTHER SIMILAR NETWORK \\ 2.1 Backbone}

Wi-Fi is a dynamic solution to establishing long-haul data communication link to distant areas, which is already in use in Bangladesh. Recently, Bangladesh Telecommunication Regulatory Commission (BTRC) has assigned $35 \mathrm{MHz}$ frequency to Augere Wireless Broadband Ltd. starting from $2.3 \mathrm{GHz}$ band and also to the Banglalion Communication Ltd. starting from $2.5 \mathrm{GHz}$ band. After that, the internet penetration of Bangladesh has increased immensely. Today the number of broadband Internet user in Bangladesh is about 0.4 million, and $56 \%$ of the towns of Bangladesh are now under wireless broadband network. To make it available to every user, BTRC has lowered the bandwidth price to some extent. But observations shows that the cost of establishing the infrastructure to reach the internet to the people of remote areas of Bangladesh is still too high. If this cost can be reduced then it will be possible for all type of users to take the advantage of lowered bandwidth cost [8].

WLAN or Wi-Fi system is used to provide wireless internet access to other systems on the local network such as other computers, shared printers, and other such devices. Typically a WLAN offers much better speed and delay within the local network than an average consumer's Internet Access. WLAN may use mesh multi-path, multi-hop wireless local area network (WLAN) for outdoor. Currently used wireless mesh networks are limited by the capacity of the wireless link, without the ability to scale throughput through aggregation of several links to transmit single IP stream, and in case of failure traffic need to reroute through alternate route using software base L3 protocols [9].

\subsection{Costs}

\subsubsection{Investment Cost}

The investment cost of a city-wide Wi-Fi project can be divided into 5 categories and all these cost elements are required to build up that network [10]:

- $\quad$ Equipment Cost-Hardware and maintenance

- Engineering Cost -Site planning, site survey, equipment installation and site construction

- $\quad$ Site Cost -Site acquisition, rental and electricity

- Backhaul Cost -Internet backbone setup and rental

- Operation Cost -Network management systems, customer and organizational supports

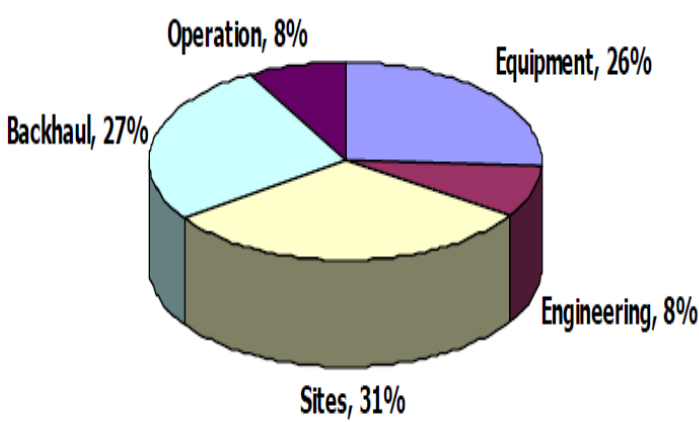

Fig. 2: Cost elements of city-wide Wi-Fi network with cost percentage of the total investment

From this figure, site cost and backhaul cost are the two largest cost elements and occupy $31 \%$ and $27 \%$ of the total investment respectively. So, by choosing appropriate Wi-Fi system that can lower these two large cost elements, the total investment cost can be greatly reduced.

The two major backhaul architecture found in outdoor Wi-Fi systems are:

1. mesh

2. cellular

Mesh architecture system uses self-healing network resilience to prevent single point of failure on backhaul. On the other hand, cellular system uses point-to-point or point-to-multi- 
point dedicated wireless backhauls with link integrity and backhaul resilience features. The inherit nature of mesh network is to share the same frequency channel by all the mesh nodes those are in a cluster. This creates a lot of problems on throughput, hopping capability, latency and system capacity; which are not created in a cellular system.

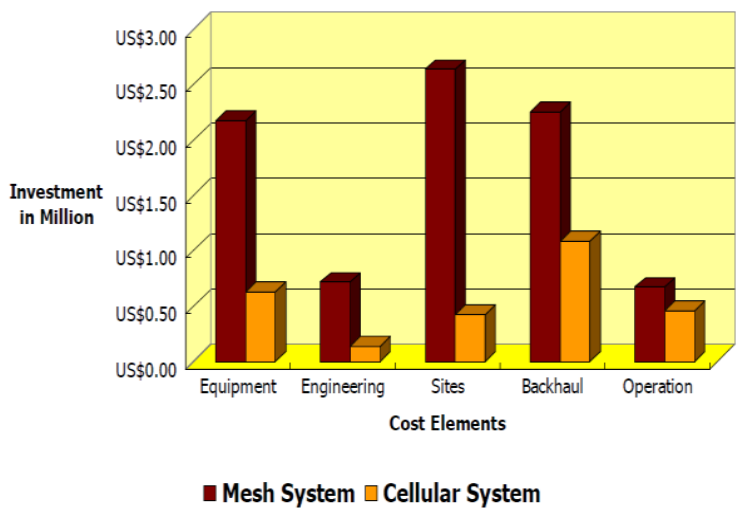

Fig. 3: Cost comparisons of mesh and cellular systems

Research shows that cellular system, the technology used by Altai A8 Wi-Fi system, can provide larger coverage in area per access point and therefore can reduce greatly (on average $84 \%$ ) in the number of sites required for the same city coverage area. The implication is that all the above 5 cost elements can be reduced significantly. The result is that: the total project investment cost (CAPEX and OPEX) can be cut by $68 \%$. Only one third of total project investment is required.

\subsubsection{Equipment cost}

$\mathrm{Wi}-\mathrm{Fi}$ routers, Wi-Fi networking adapters are needed to establish a Wi-Fi connection. Price of Wi-Fi routers starts from $1800 \mathrm{Tk}$. approx. (about \$23) and that of Wi-Fi networking adapters starts from $600 \mathrm{Tk}$. approx. (about \$8) [11].

\subsubsection{Establishment cost}

- A simple WLAN (Wireless Local Area Network) for a coffee shop or similar small places needs a broadband high speed internet connection and a router/access point/gateway broadcast device. This will enable multiple users within 100-300 feet or so of the broadcast device to share the broadband connection.

- A business class cable, satellite or DSL broadband connection costs approximately $\$ 60$ per month. If such connection already exists, this cost is ignored.

- $\quad$ Broadcast devices will cost from 40 - \$100.

- Users will need to install a Wireless or Ethernet adapter in their devices (PCs, laptops, mobile phones etc.) just for the configuration.

So, basic setup hardware costs for setting up a Wi-Fi network can be as little as $\$ 40$ and monthly broadband connection costs will be around $\$ 80-150$ [12].

\subsubsection{Maintenance cost}

According to a research, the average cost of building and maintaining a municipal wireless network is $\$ 150,000$ per square mile over 5 years ( $\$ 30000$ in a year). The research report has found out that about half of today's initiatives to create city or county-backed wireless networks will not even break, even if they charge end users as much as $\$ 25$ per month in subscription fees [13].

\subsection{Range}

Primarily, the range of a Wi-Fi network depends on the number and type of wireless access points used to build it. A traditional home network having only one wireless router can cover a single family dwelling but not much. Business networks with grids of access points can cover large office buildings. Again, the Wi-Fi signal range of any given access point also varies from device to device. The factors that determine the range of a single access point include:

- the specific 802.11 protocol it runs

- the strength of the device transmitter

- the nature of physical obstructions and/or radio interference in the surrounding area

Now-a-days Wi-Fi routers operating on the traditional 2.4 $\mathrm{GHz}$ band can reach up to 150 feet $(46 \mathrm{~m})$ indoors and 300 feet $(92 \mathrm{~m})$ outdoors. Older 802.11 a routers that could ran on $5 \mathrm{GHz}$ bands reached approximately one-third of these distances. Today $802.11 \mathrm{n}$ and $802.11 \mathrm{ac}$ routers that operate on both $2.4 \mathrm{GHz}$ and $5 \mathrm{GHz}$ bands vary in the reach similarly. In practical, physical obstructions in homes such as brick walls and metal frames or siding reduce the range of a Wi-Fi network by $25 \%$ or more [14].

\subsection{Accessibility}

Increasing the number of Wi-Fi access points provides network redundancy, better range, support for fast roaming and increased overall network-capacity by using more channels or by defining smaller cells. Except for the smallest implementations (such as home or small office networks), Wi-Fi implementations have moved toward "thin" access points. This approach provides people with more of the network intelligence housed in a centralized network appliance, relegating individual access points to the role of "dumb" transceivers. Outdoor applications may use mesh topologies. When multiple access points are deployed they are often configured with the same SSID and security settings to form an "extended service set". Wi-Fi client devices will typically connect to the access point that can provide the strongest signal within that service set.

\subsection{Performance of Wi-Fi routers}

The download and upload speeds of wireless connections are much slower than a Wi-Fi connection. Customers in areas with $4 \mathrm{G}$ wireless service can receive download and upload speeds of up to 9.12 and 5.86 Mbps respectively. The speeds on $3 \mathrm{G}$ networks are relatively slower. On the other hand, a modern Wi-Fi router compatible with the 802.11n communication standard, supports transfer speeds of up to 300 Mbps [15] [16].Throughput of these routers are higher than other type of router too. Wi-Fi routers can have throughputs higher than $900 \mathrm{Mbps}$ [17].

\section{PROPOSED ARCHITECTURE}

This paper represents a new type of architecture for mobile phone network using Wi-Fi devices in the metropolitan area of Dhaka, Bangladesh. The architecture is described below using some important criteria:

\subsection{Cost Effectiveness}

Let, there is an area of 35 kilometers covered by one single cellular phone tower. This tower requires a high price of device, land cost for placing it, establishment cost on that 
land, running and maintenance cost of tower after establishing. Establishment and maintenance of a cell tower costs vary widely, depending on what kinds of deals the constructor has with various vendors. Generally, constructing a tower costs around $\$ 200,000$ or $\$ 250,000$ (according to data of January 2009). About $\$ 150,000$ of that is for "civil installation" which includes pouring concrete, the mast and its erection, backup generators, fencing, tiny air-conditioned shack, and security systems. The baseband processors, transceivers, power supplies, amplifiers etc. will require a minimum of $\$ 20,000$ to $\$ 50,000$ for the equipment. And another $\$ 25,000$ is needed for their installation. About $\$ 5000$ is required to connect the tower to the core network, depending on its location and infrastructure. These costs may be less in urban areas, where some of the civil infrastructure costs can be avoided by placing equipment on tops of buildings or other tall structures. But always there will be ongoing costs for maintenance, diesel fuel (for generators) etc. that may be tens of thousands of dollars per month, depending on the location of the tower [18].

Again, many towers can be situated in that area, each belonging to a different service provider. They do not share a tower which would have helped them to reduce the cost to some extent. But still a tower will require a huge amount of money, which can be lowered by using small Wi-Fi routers instead of large towers. Such use of Wi-Fi routers provides the following benefits:

- $\quad$ Price of devices are very low, about 1800 tk. (about \$23) [11].

- No need of separate land for placing the routers, as they will be placed on the outer body of any building

- Maintenance cost is too low compared to large towers

So in that area of 35 kilometers, at least $381 \mathrm{Wi}-\mathrm{Fi}$ routers will be needed (costing about (1800x381) tk. or 685800 tk. or about $\$ 8800$ for buying those devices) (figure 4).

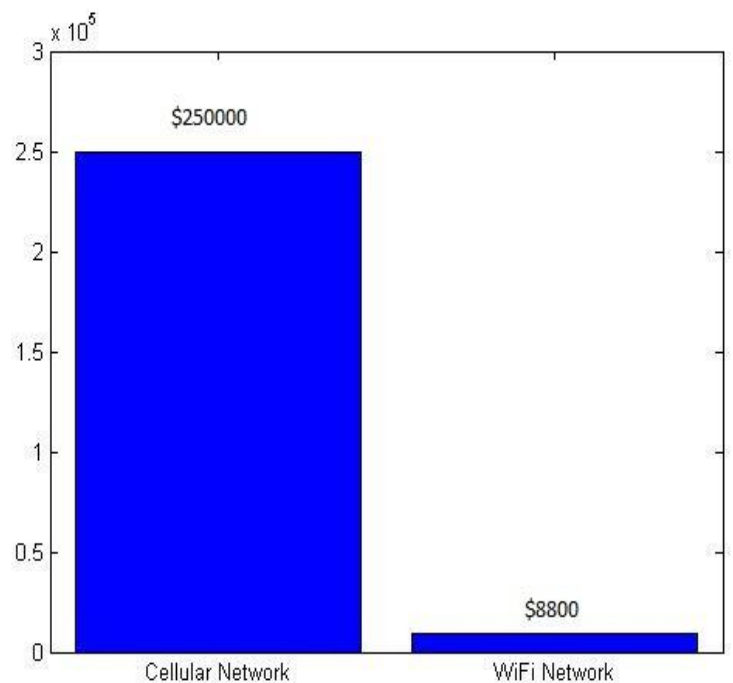

Fig. 4: Establishment cost for 2 types of networks (1 cellular tower vs.381 Wi-Fi routers)

\subsection{Shared Network}

The routers will be shared by all service providers existing in the country. So any mobile phone user will be able to receive signal in any area of the whole country, which is not possible in the tower architecture if there is no tower of that service provider in that area.

Each service provider will establish some routers in various areas (figure 5). When a user of provider $\mathrm{A}$ is in the area of $\mathrm{A}$, there is no problem in receiving service (scenario 1). But when he/she enters the area of provider $\mathrm{B}$ where there is no network coverage of $\mathrm{A}$, then $\mathrm{B}$ will provide service to that user (scenario 2). And in this case, A will pay the bill to B for providing service to its clients. This kind of handover will eliminate the current problems such as:

- No network coverage in an area for some specific service providers who do not have their own tower in that area

- Stopped data service while entering a new cell, where there is no tower of the service provider of the user's mobile phone

- No change in data rate for any user even if they enter the area of another service provider

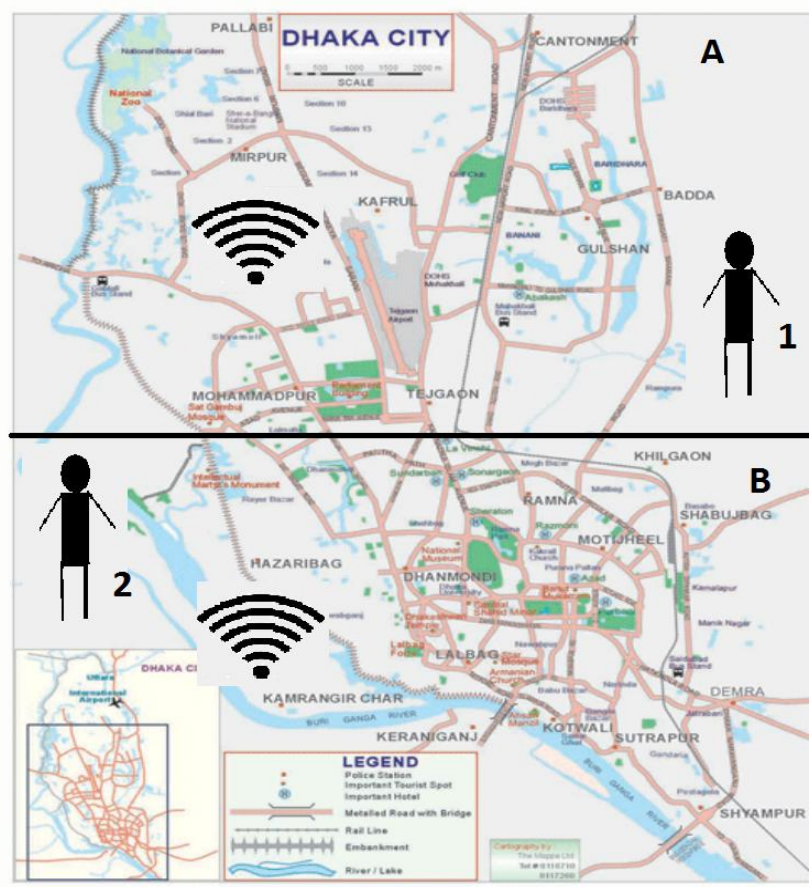

Fig. 5: Sharing Wi-Fi network between 2 different mobile service providers

\subsubsection{Details of handover}

Handover between two different networks of two different mobile phone service providers at the time of entering a new area should be performed in existing manners. The process is as follows:

- There will be different gateways for each service provider. Gateways of two contributing service providers will contact each other to handover one's user to other.

- Each gateway is connected to load balancer, router, switch, access point and end device. The server can be connected in any appropriate place between gateway and end user to provide internet service to a mobile phone user through his/her phone. 
- Only the servers are responsible to provide internet connection to the user. So this kind of handover will take place to switch from one mobile network to another, and then the user will be provided internet connection from the server of the current network.

- As there are sufficient Wi-Fi routers to serve too much users, they will be able to enjoy continuous data service in the same rate.

\subsection{Incresed Number of Users}

In today's Dhaka city, multiple electronic devices are used by most people, especially the youngsters. They use SIM cards from different service providers for different devices. Because different service providers have different network coverage, network strength, cost of voice and data etc. Most of today's smart devices are Wi-Fi enabled. So the proposed architecture of this paper will be suitable for these devices. All types of users of this metropolitan city will be benefitted with this new architecture, as they will receive high data rate with sufficient network strength and reduced cost no matter what SIM cards they are using. Thus more new users will be motivated to use data service provided by this new architecture of network.

\section{CONCLUSION}

The proposed architecture shows use of Wi-Fi system which supports up to $4 \mathrm{G}$ network. It will use the existing mobile phone network of Dhaka city for implementation. This will allow the thousands of mobile phone users of this city to enjoy the new low cost, fast, continuous data flow without making any change in their SIM cards' data plan. This architecture will attract more people to use internet in their mobile phones while in the go, without caring about the network coverage

\section{REFERENCES}

[1] A. A. M. Shohag, "3G Technology in Bangladesh," The Daily Sun, 24 June, 2011.

[2] "Fixed broadband Internet subscribers: Bangladesh 2009," [Online]. Available: http://search.worldbank.org/quickview?name=Fixed+bro adband+\%3Cem $\% 3$ EInternet $\% 3 \mathrm{C} \% 2 \mathrm{Fem} \% 3 \mathrm{E}+$ subscrib ers\&id=IT.NET.BBND\&type $=$ Indicators \&cube_no $=2 \&$ qterm=Internet+users+Bangladesh.

[3] "Birth of Broadband," International Telecommunication Union, 2003.

[4] "Internet users (per 100 people) | Data | Table," [Online]. Available:http://data.worldbank.org/indicator/IT.NET.U SER.P2/countries/.

[5] I. Islam, Bangladesh Telecoms Sector Challenges \& Opportunities, AT Capital Research, 2010.
[6] "GDP per capita (current US\$) | Data | Table," [Online]. Available:

http://data.worldbank.org/indicator/NY.GDP.PCAP.CD.

[7] A. K. Azad and N. Islam, "Overview of Internet Access in Bangladesh: Impact, Barriers, and Solutions," in Internet Society, Kuala Lumpur, 1997.

[8] "Broadband Wireless Access | BTRC," [Online] Available: http://www.btrc.gov.bd/broadband-wirelessaccess.

[9] "MeshWirelessBackbone,"[Online].Available:http://ww w.ethernitynet.com/MeshWirelessBackbone.htm.

[10] [Online].Available:http://www.abptech.com/old/products /Altai/documents/.

[11] "Computer Source | Wireless Products," [Online] Available: http://www.computersourcebd.com/productstype/wireless+products.

[12] "Free Wi-Fi wireless high speed internet access set-up," [Online].Available:http://www.wififreenet.com/free.html

[13] "Citywide Wi-Fi costs $\$ 150,000$ per square mile in maintenance costs over 5 years | ZDNet," [Online]. Available: http://www.zdnet.com/article/citywide-wi-ficosts-150000-per-square-mile-in-maintenance-costsover-5-years/.

[14] "What is the Range of a Typical Wi-Fi Network?," [Online].

Available:http://compnetworking.about.com/cs/wirelessp roducts/f/wifirange.htm.

[15] "Wireless Technology Comparison Chart - Samples JPELECTRON.COM.”[Online].Available:http://www.jp electron.com/sample/Info\%20and\%20Documents/Wirele ss\%20Technology\%20Comparison\%20Chart/.

[16] "3G/4G Performance Map: Data Speeds for AT\&T, Sprint, T-Mobile, and Verizon | TechHive," [Online]. Available:

http://www.techhive.com/article/254888/3g_4g_perform ance_map_data_speeds_for_atandt_sprint_t_mobile_and _verizon.html.

[17] "Router Charts - WAN to LAN Throughput," [Online] Available:http://www.smallnetbuilder.com/tools/charts/r outer/view.

[18] "How much money would it cost to build a cell tower? Quora,"[Online].Available: http://www.quora.com/Howmuch-money-would-it-cost-to-build-a-cell-tower. 